\title{
Analisis Teknoekonomi Implementasi Radio Frequency Identification (RFID) dalam Distribusi Daging Ayam
}

\author{
Abdul Rahim ${ }^{\# 1}$, Imam Santoso ${ }^{\# 2}$, Retno Astuti ${ }^{* 3}$ Sucipto Sucipto ${ }^{* 4}$ \\ "Departement of Agroindustrial Technology, Faculty of Agriculture Technology, Universitas \\ Brawijaya \\ Jl. Veteran - Malang 65145 Indonesia \\ ${ }^{1}$ abdulrahimsp340@gmail.com \\ 2imamsantosodub.ac.id \\ *Halal Qualified Industry Development, Universitas Brawijaya \\ Jl. Veteran - Malang 65145 Indonesia \\ ${ }^{3}$ retno_astuti@ub.ac.id \\ ${ }^{4}$ ciptotipdub.ac.id
}

\begin{abstract}
Abstrak - Penelitian ini membahas kelayakan teknologi Radio Frequensi Identification (RFID) untuk memantau distribusi daging ayam dari perusahaan rumah potong ayam (RPA) ke konsumen perusahaan pengolah daging ayam. Tujuan penelitian ini menguji kelayakan teknoekonomi sistem traceability berbasis RFID meliputi tiga aspek yaitu teknologi, pemasaran, dan finansial. Metode analisis teknologi adalah pemantauan posisi dengan Global Positioning System (GPS), suhu, dan kelembaban box mobil selama distribusi. Analisis teknoekonomi implementasi aplikasi RFID meliputi pemasaran dan kelayakan finasial NPV, IRR, B/C Ratio, dan PP. Berdasar aspek teknologi, posisi mobil selama distribusi dapat dipantau dengan tepat dengan GPS yang terintegrasi aplikasi RFID. Aplikasi juga secara real time akurat memantau suhu dan kelembaban box mobil sehingga dapat mempertahankan kualitas daging selama distribusi. Aspek pemasaran terdapat target pasar 13 RPA di Jawa Timur. Aplikasi RFID akan dijual ke perusahaan RPA dengan harga Rp. 7.296.860 per unit dan layanan jasa operasional alat dan sistem Rp.510.780 per unit per bulan. Aspek finansial menunjukkan nilai NPV adalah Rp.259.996.894, IRR sebesar 32,14 \%, nilai B/C Ratio 2,27\%, PP 3 tahun 2 bulan. Secara umum, hasil analisis teknoekonomi aplikasi RFID pada distribusi daging ayam layak direalisasikan.
\end{abstract}

Kata kunci - Teknoekonomi, Implementasi RFID, Distribusi, Daging ayam

\section{Pendahuluan}

Radio Frequensi Identification (RFID) merupakan istilah umum pada teknologi yang menggunakan gelombang radio untuk mengidentifikasi secara otomatis barang fisik. Setelah barang dipasang tag RFID, posisinya dapat dilacak otomatis oleh gelombang radio, memberikan visibilitas inventaris lebih besar, proses bisnis dan pemantauan lebih baik. Penerapan sistem RFID dalam distribusi dapat mengoptimalkan pemantauan posisi dan mengurangi biaya [1]. Menurut Sarma [2], teknologi terkini meliputi setiap aspek yang digunakan masyarakat modern. RFID banyak digunakan untuk aplikasi komersial, pemerintah, dan penggunaan pribadi. Aplikasi komersial dan industri, RFID sering digunakan untuk melacak objek seperti kontrol inventaris.

Lee dan Chan [3], menyatakan penggunaan aplikasi RFID dalam distribusi untuk menghitung secara akurat jumlah item di titik kumpul informasi kemudian dibuat jadwal kendaraan distribusi ke pelanggan. Distribusi merupakan integrasi pengguna akhir melalui pemasok agar produk dapat dinikmati dalam waktu cepat dan tepat sasaran selama pemasaran produk. Data RFID terkirim ke server komputer melalui koneksi gelombang radio dan dimodelkan sebagai basis data produk yang disimulasikan secara sederhana. Perubahan status produk dan ada jaminan data produk yang didistribusikan [4].

Aplikasi RFID telah digunakan untuk mengontrol keamanan rantai pasok pangan di Taiwan [5], memantau kualitas dan keamanan pangan di sektor pertanian [6], [7]. RFID membatu membuat keputusan dalam memantau produk melalui data atau antarmuka dalam program komputer. Kemampuan sensor RFID untuk mengontrol produk dengan uji akurasi sistem RFID sehingga output RFID adalah data identifikasi produk untuk memenuhi standar dan meminimalkan kerusakan produk [8].

Aplikasi RFID masih jarang digunakan perusahaan RPA karena relatif dianggap mahal, khususnya di Jawa Timur. Penelitian RFID ini digunakan sebagai pemantau posisi mobil, suhu, dan kelembaban selama distribusi 
daging ayam. Kelebihan aplikasi RFID yang dikembangkan ini dibanding teknologi sebelumnya adalah aplikasi RFID ini dapat memantau suhu, kelembaban, posisi mobil, dan tag status kehalalan produk selama distribusi secara real time.

Pengunaan RFID perlu biaya operasional untuk membuat dan merawat alat RFID. Biaya pembuatan alat RFID untuk merancang RFID dengan komponen alat komputer, interface system, input system RFID, dan pengkondisi sinyal. Biaya perawatan dikeluarkan selama aplikasi RFID beroperasi. Bhattacharya [9] mengeksplorasi pendapat para ahli tentang faktor-faktor yang mempengaruhi adopsi RFID yaitu pengetahuan, desain, dan keputusan penggunaannya. Analisis teknoekonomi menggabungkan aspek teknologi dan aspek ekonomi, yang terdiri dari tiga aspek kelayakan yaitu teknologi, pemasaran, dan finansial. Tujuan penelitian ini untuk melakukan analisis kelayakan teknologi sistem traceability berbasis RFID dalam distribusi daging ayam dan mengetahui kelayakan ekonominya.

\section{Metode Penelitian}

\section{A. Kerangka Konsep Penelitian}

Kelayakan pengembangan usaha aplikasi RFID dilakukan dengan analisis teknoekonomi. Pada penelitian ini dikaji 3 aspek yaitu aspek teknologi, pemasaran, dan finansial (Gambar 1). Dengan 3 aspek di atas penilaian kelayakan implementasi dapat dipertimbangkan secara komprehensip.

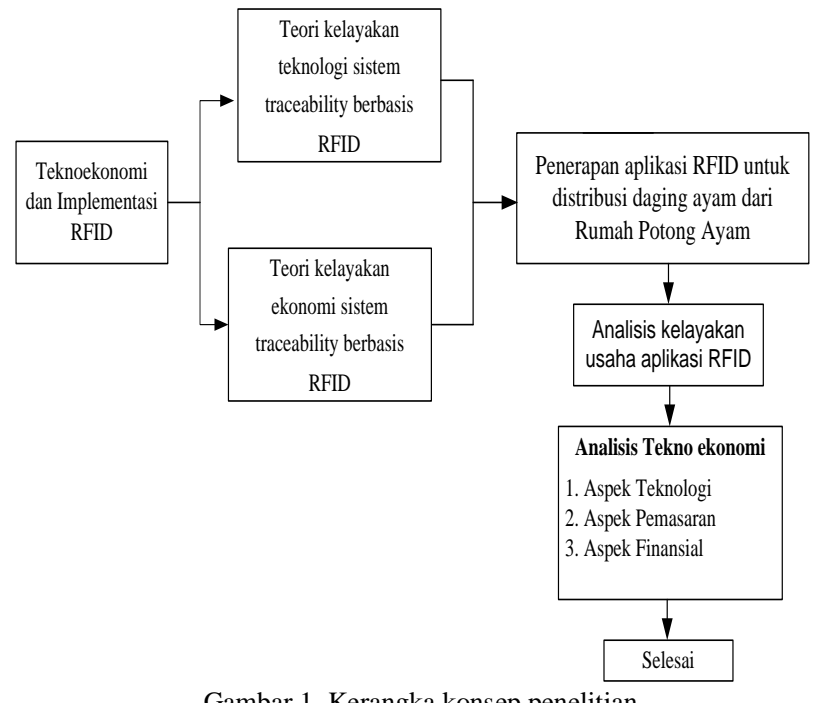

Gambar 1. Kerangka konsep penelitian

\section{B. Waktu dan Tempat Penelitian}

Penelitian pengembangan RFID di laboratorium Komputer dan Analisis Sistem, serta penerapannya di PT. RPA Kraton Indonesia Pasuruan bulan Februari - Mei 2019. Analisis ekonomi di Laboratorium Manajemen Agroindustri Jurusan Teknologi Industri Pertanian Fakultas Teknologi Pertanian Universitas Brawijaya.

\section{Data dan Sumber Data}

Data penelitian ini berupa data primer dan data sekunder, sebagai berikut:

1) Data Primer: Data primer terkait pengukuran kinerja aplikasi RFID dalam memantau posisi mobil, suhu, kelembaban, dan tag kehalalan produk diperoleh dengan simulasi penerapan di perusahaan RPA Kraton Indonesia Pasuruan. Syarat penerimaan dan penjualan produk, data pemasaran, dan logistik diperoleh dari wawancara, observasi, dan dokumentasi dari perusahaan RPA dan penyedia alat untuk membuat RFID.

2) Data Sekunder: Data sekunder didapat dari berbagai pustaka tentang analisis teknoekonomi sistem RFID dari buku, jurnal, laporan ilmiah, dan lain-lain.

\section{Analisis Data}

Data primer implementasi aplikasi RFID di perusahaan RPA Kraton Indonesia dianalisis terkait akurasi pemantauan posisi, suhu, kelembaban dalam box mobil selama distribusi. Data tersebut menjadi dasar analisis kelayakan implemtasi teknologi aplikasi RFID dalam distribusi daging ayam. Data sekunder dari studi literatur berupa informasi aplikasi RFID meliputi aspek teknologi dan ekonomi. Aspek pemasaran aplikasi RFID pada perusahaan RPA perlu studi kelayakan pemasaran untuk meningkatkan permintaan di pasar. Aspek finansial menganalisis perhitungan dengan asumsi biaya, permintaan, dan pendapatan usaha aplikasi RFID [9], [10] pada Gambar 2.

\section{HASIL DAN PEMBAHASAN}

\section{A. Aspek Teknologi}

Aspek teknologi untuk menguji manfaat aplikasi RFID pada perusahaan saat distribusi. Hal ini terkait kemampuannya untuk memberikan informasi kondisi distribusi dan operasi aplikasi RFID [11].

1) Penerapan Aplikasi RFID selama Distribusi: Perusahaan jasa teknologi RFID memproduksi aplikasi RFID dan menawarkannya ke perusahaan RPA. Aplikasi RFID dapat membantu perusahaan RPA memantau kualitas daging ayam dan mengurangi resiko kerusakannya selama distribusi. RFID dapat memantau suhu dan kelembaban dalam box mobil selama distribusi. Posisi mobil juga dapat dipantau selama distribusi melalui GPS yang terintegrasi dalam aplikasi RFID. Petugas perusahaan RPA dan konsumen perusahaan pengolah ayam sebagai tujuan distribusi dapat memantau daging ayam melalui server perusahaan terkoneksi sistem RFID. RFID reader mengidentifikasi setiap produk dengan kode produk yang disimpan dalam label RFID yang dicetak dalam fase pengolahan [12], [13]. Data RFID dapat digunakan kembali dengan sensor yang ditambahkan dalam fase pengolahan dan dihapus dari kotak pada pengiriman ke konsumen. Perangkat pada RFID dapat 
mengidentifikasi dan menetapkan kondisi produk, serta menghubungkan setiap langkah pada aplikasi komputer untuk menghasilkan informasi yang diunggah ke repositori EPCIS server [14]. Informasi ini dengan mudah dapat diakses oleh para pengguna.

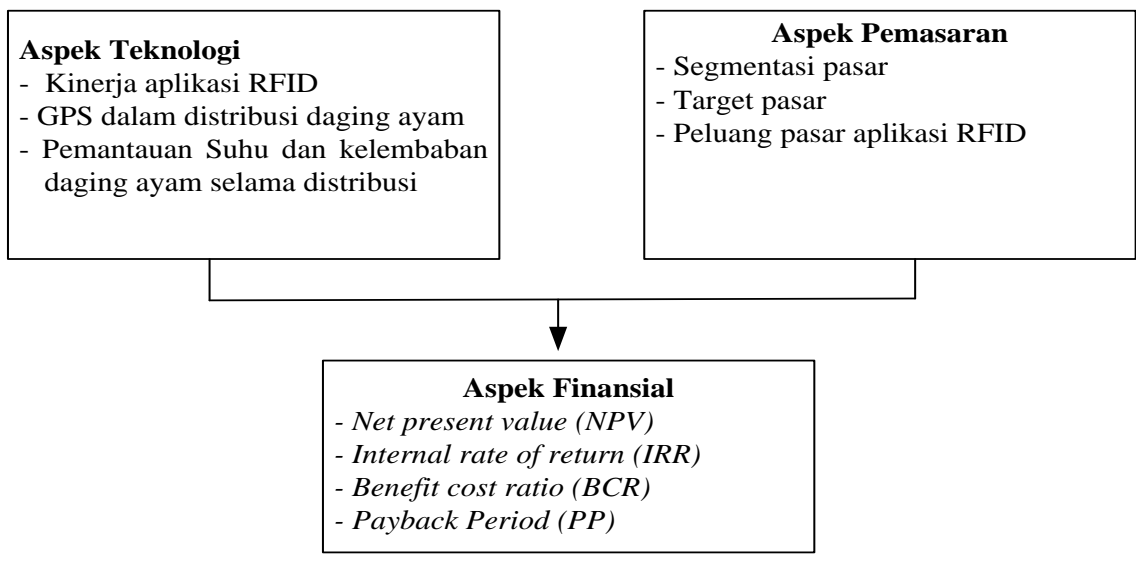

Gambar 2. Bagan analisis teknoekonomi

Pada simulasi implementasi aplikasi RFID (Gambar 3), petugas perusahaan RPA dapat memantau kondisi daging ayam selama distribusi melalui hand phone yang terkoneksi sistem aplikasi RFID. Setiap 1 box mobil berkapasitas 1,5 ton atau 2,5 ton daging ayam didistribusikan ke setiap konsumen perusahaan pengolah daging ayam, seperti hotel, restoran, ketering. Yusianto
[15] menyatakan aplikasi RFID memudahkan perusahaan RPA memantau daging ayam saat distribusi ke konsumen RPA. Konsumen RPA juga dapat mengontrol dan mendapat informasi kondisi pesanan daging ayam melalui website atau hand phone yang terkoneksi sistem RFID. Hal ini menumbuhkan kepercayaan pada perusahaan RPA.

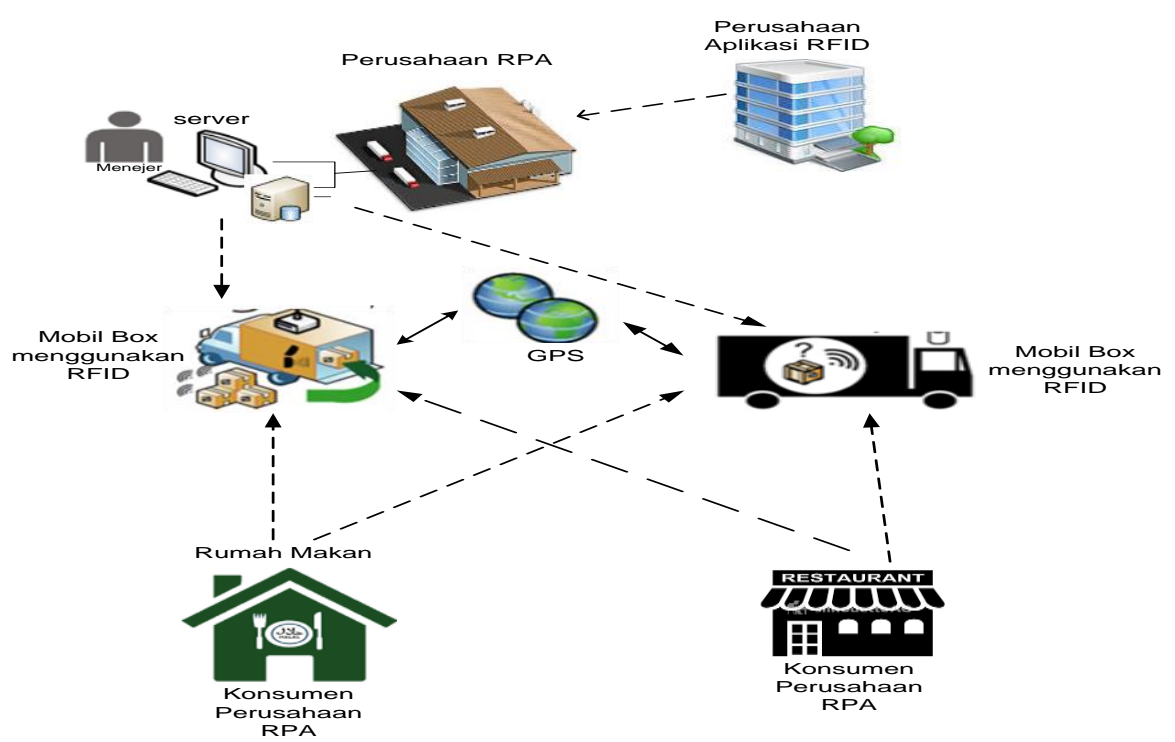

Gambar 3. Alur penggunaan aplikasi RFID dalam mengontrol produk daging ayam selama distribusi

2) Pemantauan Posisi Mobil melalui Global Positioning System (GPS): Melalui Global Positioning System (GPS) yang telah diintegrasikan dalam aplikasi RFID dapat menunjukkan posisi mobil selama distribusi dari RPA ke konsumen perusahaan pengolah daging ayam. Hasil simulasi implementasi aplikasi RFID daging ayam dari RPA Kraton Indonesia didistribusikan sejauh $14 \mathrm{Km}$ ke rumah makan Geprek Bensu di Pasuruan Jawa Timur, seperti pada Gambar 4.
Saat mobil dalam perjalanan dapat dipantau posisinya mengunakan sistem RFID, sehingga membantu perusahaan RPA memantau produk selama distribusi daging ayam ke konsumen pengolah daging ayam. Fontaine et al. [16] menyatakan sistem RFID dan GPS dieksplorasi untuk memantau produk, baik di dalam maupun di luar ruang. RFID dan GPS sebagai alat pemantau posisi mobil barang saat distribusi [17]. Saat ini teknologi RFID telah berdampak positif pada perusahaan 
dalam distribusi ditunjang GPS. Jaringan satelit GPS yang terintegrasi dalam aplikasi RFID yang dikembangkan telah dapat melacak dan memberi informasi posisi mobil secara tepat saat pengiriman daging ayam ke konsumen perusahaan pengolah ayam.

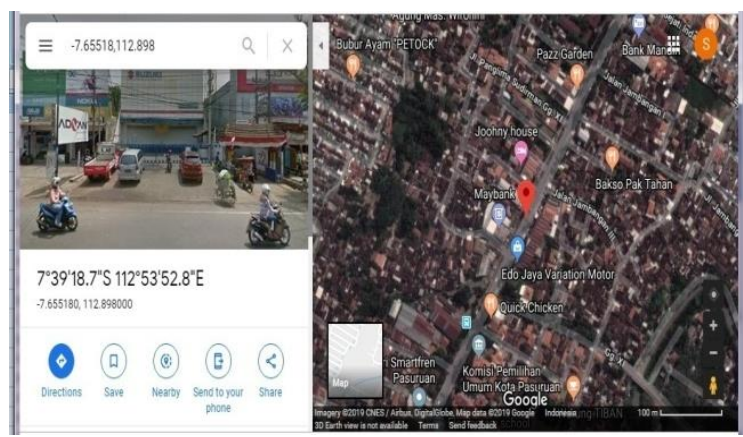

Gambar 4. Global Positioning System (GPS) posisi mobil selama distribusi daging ayam

3) Pemantauan Suhu dan Kelembaban Daging Ayam Selama Distribusi: Selama distribusi kondisi suhu dan kelembaban box mobil penting dikontrol untuk mempertahankan kualitas daging ayam. Dengan kontrol suhu dan kelembaban penurunan kualitas daging ayam akibat mikroba dan fisiologis dapat diminimalkan. Mikroba penyebab kerusakan daging ayam tumbuh cepat bila suhu melebihi $4^{\circ} \mathrm{C}$ dan kelembaban kurang dari $50 \%$ selama distribusi 10 jam. Kerusakan daging ditentukan suhu dan kelembaban [18]. Hasil pemantauan suhu selama simulasi implementasi RFID pada Gambar 5.

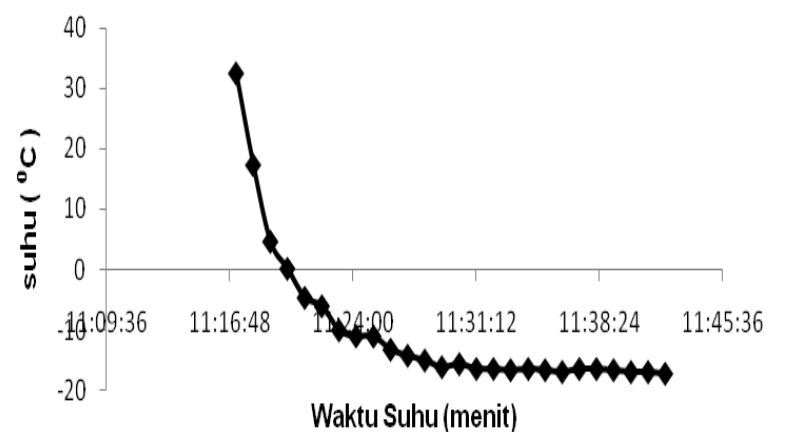

Gambar 5. Perubahan suhu selama waktu pengujian RFID

Dari Gambar 5 diketahui jam 11:17:10 suhu awal $32,6^{\circ} \mathrm{C}$ sampai jam 11:21:11 suhu menurun hingga $-4,6^{\circ} \mathrm{C}$. Penurunan suhu dari suhu awal perlu waktu kurang lebih 4,11 menit. Pada jam 11:24:11 mencapai suhu $-11^{\circ} \mathrm{C}$ perlu waktu kurang lebih 7,11 menit dari suhu awal. Suhu box mobil standar untuk distribusi daging ayam yaitu sekitar $17^{\circ} \mathrm{C}$ dapat tercapai pada jam 11:42:15 atau perlu waktu kurang lebih 25,15 menit dari suhu awal. Semakin dingin suhu standar semakin lama waktu untuk mencapai kondisi tersebut.

Hasil pemantauan kelembaban mobil box selama simulasi aplikasi RFID dapat dilihat pada Gambar 6. Saat awal simulasi daging ayam dimasukkan posisi pintu box mobil terbuka, sehingga kelembaban turun sangat cepat dengan waktu kurang lebih 1 menit. Setelah pintu mobil ditutup pada jam 11:23:11 kelembaban mulai naik 19\%. Kelembaban mencapai target di atas $50 \%$ memerlukan waktu 5 menit.

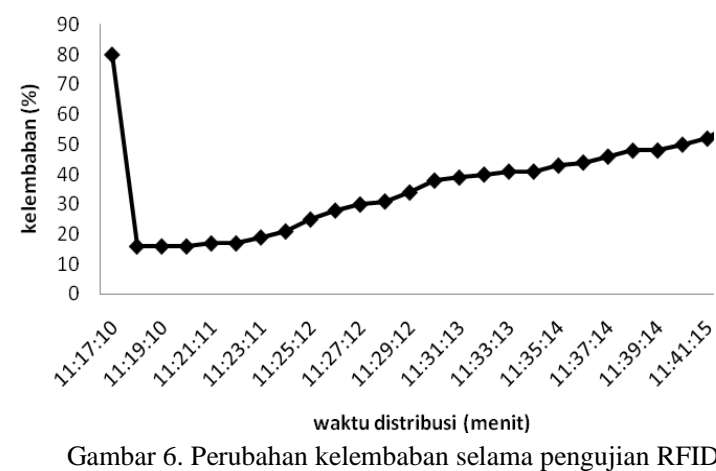

\section{B. Aspek Pemasaran}

Pendirian suatu usaha harus memiliki pasar potensial yang jelas untuk mengenalkan dan memasarkan barang atau jasa [19]. Karena itu, segmentasi dan target pasar aplikasi RFID yang dikembangkan perlu diidentifikasi.

1) Segmentasi Pasar: Segmentasi pasar merupakan proses memilih pasar dalam kelompok konsumen yang sama, kemudian memilih kelompok atau individu yang paling tepat [20]. Salah satu segmen usuha jasa aplikasi RFID adalah perusahaan RPA. Setelah aplikasi RFID dibeli perusahaan RPA, perusahaan penyedia aplikasi RFID masih memiliki ikatan untuk mengontrol operasional aplikasi RFID. Setiap bulan aplikasi dikontrol teknisi dan programmer perusahaan aplikasi RFID yang biayanya dibebankan ke perusahaan RPA.

2) Target Pasar: Target pasar merupakan segmen yang menjadi fokus pemasaran [21]. Aplikasi RFID sangat berpeluang dipasarkan ke perushaan RPA, karena aplikasi ini telah didesain untuk dapat memantau kondisi daging ayam selama distribusi. Dalam simulasi target pasar aplikasi RFID ini dipasarkan di Jawa Timur. Terdapat 13 perusahaan RPA di Jawa Timur yang menjadi target pasar aplikasi RFID, seperti Tabel 1.

\section{Aspek Finansial}

Modal usaha adalah biaya investasi dalam aktiva tetap, hingga modal kerja seperti biaya, pembelian bahan dan alat-alat produksi FRID, dan biaya tenaga kerja [22]. Jumlah investasi usaha aplikasi RFID adalah Rp.200.000.000. Asumsi perhitungan yang digunakan antara lain:

1. Alat aplikasi RFID diperkirakan berumur 5 tahun.

2. Suku bunga mengacu Bank Rakyat Indonesia (BRI) dengan kredit usaha rakyat (KUR) mikro sebesar 7\% untuk Usaha Kecil Menengah (UKM) dengan masa kredit 5 tahun [23].

3. Pajak pendapatan sesuai pasal 2 UU nomor 23 tahun 2018. Penghasilan Kena Pajak (PKP), jika pendapatan di bawah Rp. 4.800.000.000 dibebankan pajak 0,5\% [24]. 
TABEL I

PERUSAHAAN Rumah Potong AYAM (RPA) DAN JUMLAH MobiL DISTRIBUSI

\begin{tabular}{|l|l|c|}
\hline No & \multicolumn{1}{|c|}{ Nama Perusahaan RPA } & $\begin{array}{c}\text { Jumlah mobil } \\
\text { distribusi }\end{array}$ \\
\hline 1 & RPA Wahana & 1 unit \\
\hline 2 & RPA Suci Raharjo & 2 uint \\
\hline 3 & PT. Saliman Riyanto & 3 unit \\
\hline 4 & PT.RPA Kraton Indonesia & 3 unit \\
\hline 5 & RPA Puri Pangan Sejati & 4 unit \\
\hline 6 & PT. Eloda Mitra & 4 unit \\
\hline 7 & PT. Ferodatama Mukti Jaya & 4 unit \\
\hline 8 & PT. Sekar Bumi & 5 unit \\
\hline 9 & PT. Ciomas Adi Satwa & 5 unit \\
\hline 10 & PT. Suryajaya Abadi Perkasa & 5 unit \\
\hline 11 & PT. Gudang Ayam & 5 unit \\
\hline 12 & PT. Beefeather Meat Indonesia & 6 unit \\
\hline 13 & $\begin{array}{l}\text { PT. Wonokoyo Jaya } \\
\text { Corporindo }\end{array}$ \\
\hline
\end{tabular}

Sumber: Dinas Peternakan Jawa Timur (2019)

TABEL II

BIAYA KOMPONEN UNTUK SATU UNIT APLIKASI RFID

\begin{tabular}{|l|c|c|r|r|}
\hline $\begin{array}{l}\text { Nama } \\
\text { Komponen }\end{array}$ & Jumlah & Satuan & $\begin{array}{r}\text { Harga per } \\
\text { Unit (Rp) }\end{array}$ & \multicolumn{1}{c|}{$\begin{array}{c}\text { Harga } \\
\text { Total (Rp) }\end{array}$} \\
\hline $\begin{array}{l}\text { RFID } \\
\text { reader } \\
\text { MFRC-522 }\end{array}$ & 2 & unit & 60.000 & 120.000 \\
\hline ESP8266 & 1 & unit & 40.000 & 40.000 \\
\hline $\begin{array}{l}\text { Arduino } \\
\text { pro } \\
\text { Mini }\end{array}$ & 1 & unit & 55.000 & 55.000 \\
\hline Node MCU & 2 & unit & 65.000 & 130.000 \\
\hline $\begin{array}{l}\text { Rangkaian } \\
\text { pengkondisi } \\
\text { sinyal } \\
\text { PT100 }\end{array}$ & 1 & unit & 114.600 & 114.600 \\
\hline $\begin{array}{l}\text { Sensor suhu } \\
\text { PT100 }\end{array}$ & 1 & unit & 130.000 & 130.000 \\
\hline $\begin{array}{l}\text { Sensor } \\
\text { kelembaban } \\
\text { DHT11 }\end{array}$ & 1 & unit & 32.000 & 32.000 \\
\hline $\begin{array}{l}\text { Board PCB } \\
\text { System }\end{array}$ & 1 & unit & 1.000 & 120.000 \\
\hline IC INA125 & 1 & unit & 150.000 & 150.000 \\
\hline $\begin{array}{l}\text { GPS ublox } \\
\text { neo M8N }\end{array}$ & 1 & unit & 355.000 & 355.000 \\
\hline $\begin{array}{l}\text { Box } \\
\text { package } \\
\text { RFID }\end{array}$ & 2 & unit & 55.000 & 110.000 \\
\hline $\begin{array}{l}\text { Box } \\
\text { package } \\
\text { sensor }\end{array}$ & 1 & unit & 85.000 & 85.000 \\
\hline $\begin{array}{l}\text { Adaptor 12 } \\
\text { Volt }\end{array}$ & 2 & unit & 40.000 & 80.000 \\
\hline Jumlah & 1.521 .000 \\
\hline
\end{tabular}

1) Komponen Biaya Bahan Pembuatan Aplikasi RFID: Komponen biaya bahan pembuatan teknologi adalah biaya yang dihitung dengan cara menjumlahkan semua harga pokok bahan baku produksi. Biaya bahan baku diperlukan untuk mengembangkan dan membuat suatu teknologi baru [25]. Terdapat 14 komponen bahan yang digunakan dalam pembuatan aplikasi RFID. Komponen tersebut telah memenuhi standar untuk dapat mendeksi posisi, suhu, kelembaban dalam box mobil, dan tag kehalalan produk. Biaya setiap komponen untuk membuat aplikasi RFID pada Tabel 2.

2) Komponen Biaya Building System Aplikasi RFID: Biaya membangun sistem sangat penting untuk pengembangan perangkat lunak sistem aplikasi RFID. Perangkat untuk mengontrol dan mengatur efisiensi pada seluruh proses pengembangan perangkat lunak sistem aplikasi RFID. Akurasi biaya perangkat lunak sangat penting [25]. Perhitungan biaya merupakan faktor penentu keberhasilan proyek pengembangan dan pembuatan perangkat lunak. Biaya terlalu kecil mengakibatkan perangkat lunak yang dihasilkan berkualitas rendah, sebaliknya, biaya yang terlalu besar mengakibatkan pemborosan pengeluaran [26]. Biaya building system pada penelitian ini adalah biaya pemograman dan perakitan untuk masing-masing satu komponen aplikasi RFID. Biaya yang dikeluarkan dalam pemograman dan perakitan sistem aplikasi RFID, dapat dilihat pada Tabel 3. TABEL III

KOMPONEN BIAYA BUILDING SYSTEM RFID

\begin{tabular}{|l|c|c|}
\hline \multicolumn{1}{|c|}{$\begin{array}{c}\text { Biaya Building } \\
\text { System RFID }\end{array}$} & Jumlah & Biaya (Rp) \\
\hline Sensor suhu & 1 & 150.000 \\
\hline Sensor kelembaban & 1 & 50.000 \\
\hline Sim 900 & 1 & 150.000 \\
\hline GPS & 1 & 150.000 \\
\hline RFID tag / reader & 1 & 150.000 \\
\hline Web design & 1 & 550.000 \\
\hline \multicolumn{1}{|c|}{ Total Biaya } & & $\mathbf{1 . 2 0 0 . 0 0 0}$ \\
\hline
\end{tabular}

3) Pendapatan: Pelaku usaha selalu ingin mencapai pendapatan dan laba bersih yang optimum. Harga jual dan realisasi biaya produksi sangat berpengaruh terhadap kebehasilan pencapaian tujuan usaha sehingga mencapai pendapatan dan laba maksimal [27]. Penentuan harga penting diperhatikan, karena harga sangat berpengaruh terhadap laku dan tidaknya suatu barang dan jasa yang dipasarkan [23]. Penentuan harga aplikasi RFID ada 2 bagian yaitu:

1. Harga jual aplikasi RFID adalah Rp. 7.296.860 per unit RFID. Penentuan harga berdasar harga pokok produksi (HPP).

2. Harga jasa layanan operasional aplikasi RFID yaitu Rp.510.780 per unit RFID per bulan. Penentuan harga jasa layanan operasional aplikasi RFID diasumsikan 7\% dari harga pokok penjualan (HPP). 
Pendapatan merupakan hasil penjualan yang didapatkan secara langsung tanpa dikurangi biaya investasi [19]. Pendapatan usaha aplikasi RFID dari penjualan aplikasi RFID dan jasa layanan operasional aplikasi RFID. Tabel 4 menunjukkan simulasi pendapatan usaha jasa aplikasi RFID. Pada tahun ke 1 belum mencapai target pendapatan.
Tahun ke 2 sampai tahun ke 5 target pendapatan dapat tercapai dan selalu meningkat.

TABEL IV

PENDAPATAN UsAHA APLIKASI RFID

\begin{tabular}{|l|c|c|c|c|c|}
\hline \multicolumn{1}{|c|}{ Penjualan } & $\begin{array}{c}\text { Tahun 1 } \\
\text { (Rp) }\end{array}$ & $\begin{array}{c}\text { Tahun 2 } \\
(\mathbf{R p})\end{array}$ & $\begin{array}{c}\text { Tahun 3 } \\
(\mathbf{R p})\end{array}$ & $\begin{array}{c}\text { Tahun 4 } \\
(\mathbf{R p})\end{array}$ & $\begin{array}{c}\text { Tahun 5 } \\
(\mathbf{R p})\end{array}$ \\
\hline Alat (perangkat) RFID & 43.781 .160 & 51.078 .020 & 58.374 .880 & 72.968 .600 & 80.265 .460 \\
Jasa layanan aplikasi RFID & 61.293 .600 & 104.199 .120 & 153.234 .000 & 208.398 .240 & 294.209 .280 \\
Total & $\mathbf{1 0 5 . 0 7 4 . 7 6 0}$ & $\mathbf{1 5 5 . 2 7 7 . 1 4 0}$ & $\mathbf{2 1 1 . 6 0 8 . 8 8 0}$ & $\mathbf{2 8 1 . 3 6 6 . 8 4 0}$ & $\mathbf{3 7 4 . 4 7 4 . 7 4 0}$ \\
\hline
\end{tabular}

4) Cash Flow: Menurut Kasmir dan Jafar [19], unsur cash flow yaitu pendapatan inflow), pengeluaran (out flow), keuntungan bersih (benefit). Cash flow usaha jasa aplikasi RFID selama 5 tahun dinjukkan pada Tabel 5. Pada tahun ke 1 laba bersih masih minus karena masih tahap pengembalian modal. Tahun ke 2 pendapatan sudah positif tetapi masih relative kecil. Pada tahun ke 3 sampai tahun ke 5 laba bersih semakin besar seiring peningkatan pasar aplikasi RFID.

TABEL V

CASH FLOW USAHA APLIKASI RFID

\begin{tabular}{|l|r|r|r|r|r|}
\hline \multicolumn{1}{|c|}{ Uraian } & \multicolumn{1}{c|}{$\begin{array}{c}\text { Tahun 1 } \\
\text { (Rp) }\end{array}$} & \multicolumn{1}{c|}{$\begin{array}{c}\text { Tahun 2 } \\
(\mathbf{R p})\end{array}$} & \multicolumn{1}{c|}{$\begin{array}{c}\text { Tahun 3 } \\
\text { (Rp) }\end{array}$} & \multicolumn{1}{c|}{$\begin{array}{c}\text { Tahun 4 } \\
\text { (Rp) }\end{array}$} & \multicolumn{1}{c|}{$\begin{array}{c}\text { Tahun 5 } \\
\text { (Rp) }\end{array}$} \\
\hline Pendapatan & 105.074 .760 & 155.277 .140 & 211.608 .880 & 281.366 .840 & 374.474 .740 \\
Pengeluaran/biaya & 88.652 .000 & 90.768 .000 & 92.884 .000 & 95.000 .000 & 113.187000 \\
Laba & 16.422 .760 & 64.509 .140 & 118.724 .880 & 186.366 .840 & 261.287 .740 \\
Laba bersih Sebelum bunga & & & & \\
(EBT) & -5.744 .360 & 56.764 .780 & 118.724 .880 & 186.366 .840 & 261.287 .740 \\
Bunga bank 7\% & 3.500 .000 & 2.800 .000 & 2.100 .000 & 1.400 .000 & 700.000 \\
Laba sebelum pajak (EAT) & -9.244 .360 & 55.964 .780 & 116.624 .880 & 184.966 .840 & 260.587 .740 \\
Pajak penghasilan 0,5\% & 49.892 & 319.046 & 590.124 & 928.334 & 1.302 .939 \\
Laba bersih & -9.198 .138 & 55.684 .956 & 116.041 .756 & 184.738 .506 & 259.284 .801 \\
\hline
\end{tabular}

TABEL VI

KELAYAKAN FINANSIAL USAHA APLIKASI RFID

\begin{tabular}{|c|c|c|c|c|c|}
\hline No & Kriteria & Satuan & $\begin{array}{c}\text { Kriteria } \\
\text { Kelayakan }\end{array}$ & Hasil & Kesimpulan \\
\hline $\begin{array}{l}1 . \\
2 . \\
3 . \\
4 .\end{array}$ & $\begin{array}{l}\text { NPV } \\
\text { IRR } \\
\text { B/C Ratio } \\
\text { PP }\end{array}$ & $\begin{array}{l}\text { Rp } \\
\text { Persen (\%) } \\
\text { Persen (\%) } \\
\text { Tahun }\end{array}$ & $\begin{array}{l}>1 \\
>\mathrm{DF} \\
>1 \\
<\text { Tahun }\end{array}$ & $\begin{array}{c}259.996 .894 \\
32,14 \\
2,27 \\
3,2\end{array}$ & $\begin{array}{l}\text { Layak } \\
\text { Layak } \\
\text { Layak } \\
\text { Layak }\end{array}$ \\
\hline
\end{tabular}

5) Kriteria Uji Kelayakan: Kelayakan usaha jasa aplikasi RFID memberikan keuntungan ekonomi pada perusahaan RPA. Indeks kelayakan teknologi baru berdasarkan discount factor (DF) yang dianalis melalui Net Present Value (NPV), Internal Rate Return (IRR), Benefit Cost Ratio (B/C Ratio), dan Payback Periode (PP) [19]. Nilai uji kelayakan finansial usaha jasa aplikasi RFID dapat dilihat pada Tabel 6 .

Dari Tabel 6 terlihat Net Present Value (NPV) Rp. 259.996.894 sehingga usaha RFID diyatakan layak. Internal Rate Return (IRR) hasil perhitungan sebesar $32,14 \%$ lebih besar dari suku bunga Kredit Usaha Rakyat (KUR) yaitu $7 \%$.
Benefit Cost Ratio (B/C Ratio) sebesar 2,27 lebih besar dari 1 dan Payback Periode (PP) hasil perhitungan selama 3 tahun 2 bulan. Semua kriteria kelayakan di atas menujukkan recana usaha jasa RFID layak diusahakan.

\section{KESIMPULAN DAN SARAN}

\section{A. Kesimpulan}

Secara aspek teknologi, aplikasi RFID yang dikembangkan dapat memantau secara tepat posisi mobil selama distribusi melalui GPS yang sudah diintegrasikan ke dalam aplikasi ini. Suhu dan kelembaban dalam box mobil dapat dipantau secara real time sehingga mutu daging ayam tetap terjaga. Kelayakan ekonomi dilihat dari 
aspek pemasaran dan finansial. Aspek pemasaran usaha jasa aplikasi RFID layak dikembangkan dan memiliki potensi pasar khususnya pada industri rumah potong ayam (RPA). Kelayakan finansial aplikasi RFID dengan asumsi 5 tahun menunjukkan nilai NPV positif yaitu Rp. 259.996.894, IRR 32,14\%, BC/R 2,27\%, PP 3 tahun 2 bulan. Dengan demikian jasa aplikasi RFID secara teknoekonomi layak untuk diusahakan.

\section{B. Saran}

Aplikasi RFID yang dikembangkan secara teknologi masih tahap awal, sehingga perlu penelitian untuk mengukur daya tahan alat aplikasi dalam kondisi kelembaban tinggi dalam box mobil. Pada analisis finansial perlu diteliti dan dirinci lebih lanjut biaya komponen RFID yang cepat berubah dan biaya operasional per bulan.

\section{UCAPAN TERIMAKASIH/ ACKNOWLEDGMENT}

Tim penulis mengucapkan terima kasih kepada Kementerian Riset, Teknologi, dan Pendidikan Tinggi yang telah memberikan bantuan hibah penelitan magister dan Universitas Brawijaya yang telah membantu publikasi.

\section{REFERENSI}

[1] I. H. Hong, J. F. Dang, Y. H. Tsai, C. S. Liu, W. T. Lee, M. L. Wang, dan P. C. Chen, "An RFID application in the food supply chain: A case study of convenience stores in Taiwan". J. Food Eng. Vol. 106, No. 2, pp. 119-126, 2011.

[2] S. Sarma, D. Brock, dan D. Engels, "Radio Frequency Identification and the Electronic Product Code", IEEE Comput Soc. Micro. Vol. 21 No.6. pp. $50-54,2001$.

[3] C. K. M. Lee, dan T. M. Chan, "Development of RFID based reverse logistics system", Expert Syst with Appl, Vol. 36, No. 5, pp. 9299-9307, 2009.

[4] G. Zacharewicz, J. C. Deschamps, dan J. Francois, "Distributed simulation platform to design advanced RFID based freight transportation systems". Comput in Ind, Vol. 62, No. 6, pp. 597 612, 2011.

[5] Y. M. Wang, Y. Shun Wang, dan Y. Fu Yang, "Understanding the determinants of RFID adoption in the manufacturing industry. Information Management at National Changhua University of Education, Changhua, Taiwan". Technol. Forecast Soc. Change, Vol. 77, No. 5, pp. 803-815, 2010.

[6] J. C. F. Bibi, C. Guillaume, N. Gontard, dan Sorli, "A review: RFID technology having sensing aptitudes for food industry and their contribution to tracking and monitoring of food products", Trends Food Sci. Technol, Vol. 62, pp. 91-103, 2017.

[7] C. Amador, J. P. Emond, dan M. C. do N. Nunes, "Application of RFID technology in the temperature mapping of the pineapple supply chain", Sens and Instrum. Food Qual. Saf, Vol. 3, No. 1, 2009.

[8] H. K. Danang, S. B. Purnomo, dan S. Sucipto, "Traceability implementation based on RFID at agroindustry: A review", IOP Conf. Ser: Earth. Environ. Sci, Vol. 230, No. 1, 0120170,, 2019.

[9] M. Bhattacharya, "A conceptual framework of RFID adoption in retailing using Rogers stage model" Bus. Process. Manage, Vol. 21, No.3, pp. 517-540, 2015.

[10] D. Nugraheni, dan Y. Priyandari, "Analisis teknoekonomi implementasi teknologi RFID pada sistem traceability", Seminar Internasional dan Konferensi Nasional IDEC, pp. 533-540, 2016.

[11] E. R. Subhiyakto, D. W. Utomo, dan P. W. Adi, "Teknologi dan teknik sistem terdistribusi pervasif dalam bidang logistik: Studi literatur sistematis, J. Buana. Inf, Vol. 7, No. 2, pp. 83-94, 2016.

[12] D. A. Kurniawan, "Analisis Penerapan RFID untuk menurunkan biaya logistik", J Pen Tran Multi, Vol. 13. No. 1, pp. 11 - 20, 2015.
[13] M. Tajima, "Strategic value of RFID in supply chain management, J Purch. \& Supply Manage, Vol. 13, No. 4, pp. 261-273, 2007.

[14] M. Trebar, M. Lotri, I. Fonda, A. Pletersek, dan K. Kova, "RFID data loggers in fish supply chain traceability", Intl J Antennas Propag, Vol. 9, 2013.

[15] R. Yusianto, "Pengembangan model pelayanan otomatis berbasis RFID untuk optimalisasi stok dalam rantai pasok sistem distribusi barang", Semantik. pp. 313-316, 2018.

[16] M. G. Guillemette, I. Fontaine, dan C. Caron, "Hybrid RFID-GPS real-time location system for human resources: development, impacts and perspectives", Proc. 41st Hawai Int. Conf. on Syst. Sci., pp. 1-10, 2008.

[17] K. R. Prasannaa, dan M. Hemalatha, "RFID GPS and GSM based logistics vehicle load balancing and tracking mechanism", Intl Conf. Commun. Technol. Sys Design. Procedia Eng, Vol. 30. pp. 726-729, 2011.

[18] K. H. Eom, K. H. Hyun, S. Lin, dan J. W. Kim, "The meat freshness monitoring system using the smart RFID tag". Int. J Distrib Sens Networks. Vol. 10, No. 7, 2014.

[19] Kasmir dan Jakfar, Studi kelayakan bisnis, Jakarta: Prenada Media Grouf, 2012.

[20] L. Majid, "Analisis segmentasi pasar pengguna bus wisata werkudara Surakarta", J Nas. Par. Vol. 6, No.1, 2014.

[21] W. S. Karamoy, "Strategi segmenting, targeting dan positioning pengaruhnya terhadap keputusan konsumen menggunakan produk KPR BNI Griya”. J EMBA. Vol. 1, No. 3, pp. 562-571, 2013.

[22] D. H. Basu Swasta, Manajemen Penjualan, Yogyakarta: BPFE, 2012.

[23] PT. Bank Rakyat Indonesia (Persero) [online] available: https://bri.co.id/kur, Di akses pada tanggal 30 Agustus 2019.

[24] Peraturan Pemerintah Republik Indonesia Nomor 23 Tahun 2018 tentang pajak penghasilan atas penghasilan dari usaha yang diterima atau diperoleh wajib pajak yang memiliki peredaran bruto tertentu.

[25] P M Aditya, A Rachmadi, dan S A Wicaksono, "Perhitungan Biaya Pembangunan Sistem Informasi Pariwisata Kota Sawahlunto Menggunakan Metode COCOMO II" J Pengem Teknol Info Ilmu Komp, Vol. 2, No. 11, pp. 4785-4793, 2018.

[26] D. E. Damayanti, Suprapto, dan A. R. Perdanakusuma, "Analisis estimasi biaya pembuatan perangkat lunak menggunakan metode cocomo II di Inagata Technosmith", J Pengembangan Teknol. Inf. Ilmu Komp, Vol. 1, No.10, pp. 1220-1229, 2017.

[27] E. Widodo, M. Mustafid, dan I Widiyanto, "Aplikasi sistem pendukung keputusan untuk menentukan harga layanan teknologi informasi” J Sist Info Bisnis. Vol. 4, No.3, pp. 194-204, 2014. 